\title{
Development of acute hepatotoxicity following the first dose of paliperidone palmitate: a case report
}

\author{
Esin $\operatorname{Erdogan}^{1 \oplus}$, Dursun Hakan Delibas ${ }^{1 \odot}$ \\ 'University of Health Sciences, Izmir Bozyaka Training and Research Hospital, Department of Psychiatry, Izmir - Turkey
}

\begin{abstract}
Paliperidone palmitate (PP) is a long-acting antipsychotic administered intramuscularly once a month in the acute and maintenance treatments of schizophrenia. It has been reported to be successful especially in patients with poor oral drug compliance. The most common side effects are dizziness, sleepiness, anxiety, injection site reactions, and extrapyramidal system symptoms. The aim of this study is to draw attention to a rare side effect of PP and contribute to the literature by presenting a case of high fever and high liver function tests after application of the first dose.
\end{abstract}

Keywords: Hepatotoxicity, liver enzymes, paliperidone palmitate

\section{INTRODUCTION}

The inability of schizophrenia patients to comply with the treatment still remains an important problem in the management of the disorder. It was shown that more than $35 \%$ of the patients had compliance problems in the first few weeks of treatment and only $25 \%$ were fully compliant after two years (1). Long-acting injectable (LAI) formulations of antipsychotic agents have been reported to provide advantages in the acute treatment and maintenance of schizophrenia patients having difficulties with oral medication leading to a risk of relapse $(2,3)$. Paliperidone palmitate $(P P)$, a benzisoxazole derivative which is hydrolyzed to release the active part of the paliperidone and absorbed into the systemic circulation, belongs to the latest generation of antipsychotics developed for long-term effective injection (4). Following intramuscular administration of a single dose, a higher peak concentration of $28 \%$ is observed after injection into the deltoid muscle compared to the gluteal muscle. However, after four injections, the maximum plasma concentrations between the two injection sites are balanced $(4,5)$. Therefore, administration of two initial doses into the deltoid muscle on days 1 and 8 will ensure rapid availability of therapeutic drug concentrations (6).

In addition to the benefits of atypical antipsychotic drugs for the patients, serious side effects limiting the clinical use of these new agents can be seen. Especially appropriate prescription and dosing of LAIs are required because of their long half-lives, delayed release, and risk of post-injection side effects. In terms of reliability, it has been reported that atypical antipsychotic agents can cause reversible or irreversible movement disorders such as tardive dyskinesia, increase in sleep time, weight gain, and impaired glucose and lipid metabolism (7-9). Common adverse events with PP use were headache, vomiting, limb pain, and

How to cite this article: Erdogan E, Delibas DH. Development of acute hepatotoxicity following the first dose of paliperidone palmitate: a case report. Dusunen Adam The Journal of Psychiatry and Neurological Sciences 2020;33:92-95.

Correspondence: Esin Erdogan, Izmir Bozyaka Training and Research Hospital, Department of Psychiatry, Saim Cikrikci Cad., No: 59, 35170 , Karabaglar/lzmir - Turkey

Phone: +90 2322505050 - 5009 E-mail: dresinerdogan@gmail.com

Received: May 12, 2019; Revised: May 30, 2019; Accepted: July 25, 2019 
injection site pain (10). Patients with schizophrenia who developed acute persistent circulatory failure and extrapyramidal symptoms requiring vasopressors and mechanical ventilation with death resulting after receiving injections of $\mathrm{PP}$ have been reported in the literature $(11,12)$, as have cases with delirium and liver enzyme elevation caused by PP $(13,14)$. In this article, we present a case of high fever and high liver function tests (LFT) immediately after the first dose of PP.

\section{CASE}

A male patient, aged 25 years, single, high school graduate, with a diagnosis of acute exacerbation of schizophrenia was hospitalized at the psychiatry clinic for treatment. Written informed consent for the publication of the case was obtained from the patient. The patient had been unable to work for 2 years and lived with his parents. Psychiatric examination found intense persecution and reference delusions. It was learned that he believed aliens were implanted in the bodies of his parents. He attacked his mother with a knife because of auditory hallucinations of these creatures and their neighbors interpreting and directing him. He had delusions suggesting that all his actions were followed by external cameras placed in his home. When the outpatient psychiatric clinic records were examined, it was observed that he had not been compliant with oral medication treatment for the last two years. He had discontinued his medications many times, and he reported to the emergency service with acute agitation. Routine blood tests (fasting glucose, hemogram, thyroid function tests, LFTs, urea, creatinine, hepatitis markers, lipid profile, B12, folic acid, ferritin, vitamin D) were requested on the first day of hospitalization, and results were found in the normal range. A PP injection was administered once in the inpatient service at a dose of $150 \mathrm{mg}$ because of treatment compliance problems. One day after the injection, high fever $\left(39.5^{\circ} \mathrm{C}\right)$, diarrhea, nausea, weakness, muscle pain, and increased LFT values appeared. In the physical examination, he was conscious and there was no increase in muscle tonus, there was no sign of rigidity in the neck or the four extremities. Following these developments, the patient was evaluated by specialists for infectious and internal diseases. Suggested tests were performed for medical differential diagnosis. Detailed viral, autoimmune, and serological tests were within normal limits and urine tests were negative. Serology was negative for viral hepatitis $(\mathrm{HBsAg}=0.10 \mathrm{IU} / \mathrm{mL}$, antiHBsIg G=6mIU/mL, anti-HCV=0.08S/CO), HIV (anti$\mathrm{HIV}=0.3 \mathrm{~S} / \mathrm{CO}$ ), acute infection with cytomegalovirus (Anti-CMV IgM=3S/CO), herpes simplex (HSV-1 $\operatorname{IgM}=16 \mathrm{U} / \mathrm{mL}$ ), and Epstein-Barr viruses (Anti EBV IgG $=0.4 I S R)$. Antinuclear antibody $(A N A<1 / 40)$ ), liverkidney microsomal antibody $(\mathrm{LKM}<1 / 40)$, antimitochondrial antibody $(\mathrm{AMA}<1 / 40)$, smooth muscle antibody $(\mathrm{SMA}<1 / 40)$ and perinuclear antineutrophil cytoplasmic antibody $(\mathrm{PANCA}=4 \mathrm{U})$ were also negative. Therefore, infection-induced and autoimmune causes were excluded. Upper and lower abdomen ultrasound scan was found to be normal. Acute hepatotoxicity in the patient was attributed to PP. In order to provide hydration, $3000 \mathrm{cc} /$ day balanced electrolyte solution was administered intravenously for 2 days. Peripheral cold application was performed. Body temperature returned to normal on day 4 . When the blood tests were examined retrospectively, it was determined that LFT values were increased after injection on the first day of hospitalization. (AST $=155$, $\mathrm{ALT}=200, \mathrm{GGT}=260$ ) (Table 1). CPK levels were also within the normal range. The PP 8th day dose was not administered. It was found that there was no previous medical history of any general medical illness and no liver dysfunction in the family history. At the end of the $3^{\text {rd }}$ week, LFT values gradually decreased. After LFT

Table 1: Evaluation of the patient's laboratory test results

\begin{tabular}{lccccc} 
& First day & Third day & First week & Third week & Normal range \\
\hline Hemoglobin (g/L) & 14.8 & 14.3 & 13.6 & 13.2 & $13.4-19.6$ \\
White blood cell count (mm $\mathbf{m}^{\mathbf{3}}$ & 4.280 & 6.800 & 5900 & 4800 & $2.74-6.15$ \\
Platelet count (microliters) & 284.450 & 220.603 & 260.300 & 302.100 & $150.000-400.000$ \\
Alanine aminotransferase (U/L) & 24.6 & 200 & 146.7 & 38.9 & $17.5-34.5$ \\
Aspartate aminotransferase (U/L) & 29.5 & 155 & 80.6 & 33.2 & $15-41$ \\
Alkaline phosphatase (U/L) & 78.5 & 160.4 & 80.5 & 68.4 & 0.120 \\
Y-Glutamyltransferase (U/L) & 44.2 & 260 & 150.4 & 60.5 & $0-55$ \\
Creatinine phosphokinase (U/L) & 35.4 & 98.7 & 46.6 & 34.2 & $30-200$ \\
Lactic acid dehydrogenase (U/L) & 132.2 & 440.8 & 290.5 & 160.6 & $120-220$ \\
\hline
\end{tabular}


values returned to normal, the patient was followed up for 1 week without psychotropic medication. Then, oral haloperidol $10 \mathrm{mg} /$ day was followed by treatment with lorazepam $1.25 \mathrm{mg}$ /day in order to maintain sleep continuity. The patient was discharged with partial improvement of his psychotic symptoms and without elevation in his LFT values.

\section{DISCUSSION}

In this case report, a young adult schizophrenia patient who developed acute hepatotoxicity after PP has been presented. LAI antipsychotics provide a consistent distribution of drugs, regardless of the ability or willingness to take them orally on a regular basis, reducing the risk of taking too much or too little medication intentionally or accidentally and minimizing dose deviations. Due to these advantages, they have been chosen with greater frequency in the treatment of schizophrenia over the last 10 years $(15,16)$. According to double-blind, placebo-controlled acute treatment studies, the most common adverse events associated with PP were EPS (0-5\%), injection site reactions (0-10\%), dizziness (2-6\%), and drowsiness/sedation (5-7\%). In four fixed-dose, double-blind, placebo-controlled trials, the frequency of PP therapy was reported to be $5.8 \%$ due to adverse events (10,17-19). When reviewing the literature, only few case reports about the elevation of LFT related to $\mathrm{PP}$ are found. In a female patient who had a deterioration of the LFT after the first dose of PP, it was seen that the enzyme levels returned to normal at the 6th day. After administration of the 2nd dose of PP, they increased again, and the drug was discontinued (14). Moreover, acute-onset delirium was seen after the second PP dose in an adolescent with schizophrenia (13). In our case, the use of the LAI form of haloperidol was not considered due to transaminitis reported in the literature (20-22). Risperidone-induced hepatotoxicity has also been reported in another patient using synthetic cannabinoid (23). When the patient was evaluated in terms of differential diagnosis, he did not show any evidence of autonomic system imbalance and there were no rigidity or other features indicative of neuroleptic malignant syndrome. In our case, LFT returned to a normal level in the third week, and in the long term, the patient was followed with a typical longacting antipsychotic treatment (zuclopenthixol decanoate $200 \mathrm{mg} / 2$ weeks). The role of liver metabolism in cytochrome P450 2D6 and 3A4 was limited because $60 \%$ of paliperidone was excreted unchanged in the urine. It has been reported that in case of renal insufficiency, dose adjustment is recommended for creatinine clearance, whereas in mild and moderate liver failure no dose adjustment is required (24). Although a psychotropic effect in liver failure has been suggested (25), in the presence of individual sensitivities as in this case it is appropriate to monitor LFT and other clinical parameters if fever is observed when starting PP. Our report raises clinicians' awareness of this rare side effect, thus contributing to the literature. Controlled and longitudinal studies are required to assess the short- and long-term hepatotoxic effects of PP.

\begin{tabular}{|l|l|l|}
\hline \multicolumn{4}{|l|}{ Contribution Categories } & Author Initials \\
\hline \multirow{4}{*}{ Category 1} & Concept/Design & E.E., D.H.D. \\
\cline { 2 - 3 } & Literature review & E.E., D.H.D. \\
\cline { 2 - 3 } & Data analysis/Interpretation & E.E., D.H.D. \\
\cline { 2 - 3 } & Case follow-up (if applicable) & E.E., D.H.D. \\
\hline \multirow{3}{*}{ Category 2} & Drafting manuscript & E.E., D.H.D. \\
\cline { 2 - 3 } & Critical revision of manuscript & E.E., D.H.D. \\
\hline \multirow{2}{*}{ Category 3} & Final approval and accountability & E.E., D.H.D. \\
\hline \multirow{3}{*}{ Other } & Technical or material support & N/A \\
\cline { 2 - 3 } & Supervision & N/A \\
\hline
\end{tabular}

Informed Consent: Written informed consent was obtained from the patient.

Peer-review: Externally peer-reviewed.

Conflict of Interest: Authors have not reported any conflict of interest.

Financial Disclosure: The authors did not receive any financial support.

\section{REFERENCES}

1. Nasrallah HA. The case for long-acting antipsychotic agents in the post-CATIE era. Acta Psychiatr Scand 2007; 115:260-267.

2. McEvoy JP. Risks versus benefits of different types of long-acting injectable antipsychotics. J Clin Psychiatry 2006; 67(Suppl 5):1518.

3. Coppola D, Liu Y, Gopal S, Remmerie B, Samtani MN, Hough DW, et al. A one-year prospective study of the safety, tolerability and pharmacokinetics of the highest available dose of paliperidone palmitate in patients with schizophrenia. BMC Psychiatry 2012; 12:26. [CrossRef]

4. Cleton A, Rossenu S, Hough D, Crauwels H, Vandebosch A, Berwaerts J, et al. Evaluation of the pharmacokinetic profile of deltoid versus gluteal intramuscular injections of paliperidone palmitate in patients with schizophrenia. Poster presented at the American Society for Pharmacology and Therapeutics (PI75). Orlando, FL, 2008 Apr 2-5. Clin Pharmacol Ther 2008; 83:S31. 
5. Cleton A, Rossenu S, Hough D, Crauwels H, Berwaerts J, Gopal $\mathrm{S}$, et al. Assessment of the dose proportionality of paliperidone palmitate 25, 50, 100 and $150 \mathrm{mg}$ EG. A new long-acting injectable antipsychotic, following administration in the deltoid or gluteal muscles. Poster presented at American Society for Clinical Pharmacology and Therapeutics (PI-74). Orlando, FL, 2008 Apr 2-5. Clin Pharmacol Ther 2008; 83:S31

6. Bishara D. Once-monthly paliperidone injection for the treatment of schizophrenia. Neuropsychiatr Dis Treat 2010; 7:561-572.

7. Kane JM, Barett EJ, Casey DE, Correll CU, Gelenberg AJ, Klein S, et al. Metabolic effects of treatment with atypical antipsychotics. J Clin Psychiatry 2004; 65:1447-1455. [CrossRef]

8. Nasrallah HA, Newcomer JW. Atypical antipsychotics and metabolic dysregulation: evaluating the risk/benefit equation and improving the standard of care. J Clin Psychopharmacol 2004; 24 (Suppl 1):S7-S14. [CrossRef]

9. Newcomer JW. Abnormalities of glucose metabolism associated with atypical antipsychotic drugs. J Clin Psychiatry 2004; 65 (Suppl 18):36-46.

10. Gopal S, Hough DW, Xu H, Lull JM, Gassmann-Mayer C, Remmerie BM, et al. Efficacy and safety of paliperidone palmitate in adult patients with acutely symptomatic schizophrenia: a randomized, double-blind, placebo-controlled, dose-response study. Int Clin Psychopharmacol 2010; 25:247-256. [CrossRef]

11. Fujii Y. What lessons should we learn from the death of patients on Xeplion? Psychiatry Clin Neurosci 2015; 117:132-45. (Japanese with English abstract)

12. Omi T, Kanai K, Kiguchi T, Nishida T, Fujimi S, Matsunaga $\mathrm{H}$. The possibility of the treatment for long-acting injectable antipsychotics induced severe side effects. Am J Emerg Med 2017; 35:1211e1-1211e2. [CrossRef]

13. Mirza H, Harding D, Al-Balushi N. Paliperidone palmitateinduced delirium in an adolescent with schizophrenia: case report. Sultan Qaboos Univ Med J 2018; 18:e208-e210. [CrossRef]

14. Onen S. Liver enzyme elevation after first dose of paliperidone palmitate: a case report. Bulletin of Clinical Psychopharmacology 2014; 24 (Suppl 1):S287.

15. Jones PB, Barnes TR, Davies L, Dunn G, Lloyd H, Hayhurst KP, et al. Randomized controlled trial of the effect on quality of life of second- vs first-generation antipsychotic drugs in schizophrenia: Cost Utility of the Latest Antipsychotic Drugs in Schizophrenia Study (CUtLASS 1). Arch Gen Psychiatry 2006; 63:1079-1087.

16. Crossley NA, Constante M, McGuire P, Power P. Efficacy of atypical v. typical antipsychotics in the treatment of early psychosis: meta-analysis. Br J Psychiatry 2010; 196:434-439.

17. Kramer M, Litman R, Hough D, Lane R, Lim P, Liu Y, et al. Paliperidone palmitate, a potential long-acting treatment for patients with schizophrenia. Results of a randomized, double-blind, placebo-controlled efficacy and safety study. Int J Neuropsychopharmacol 2010; 13:635-647. [CrossRef]

18. Nasrallah HA, Gopal S, Gassmann-Mayer C, Quiroz JA, Lim $\mathrm{P}$, Eerdekens $\mathrm{M}$, et al. A controlled, evidence-based trial of paliperidone palmitate, a long-acting injectable antipsychotic, in schizophrenia. Neuropsychopharmacology 2010; 35:2072-2082.

19. Pandina GJ, Lindenmayer JP, Lull J, Lim P, Gopal S, Herben $\mathrm{V}$, et al. A randomized, placebo-controlled study to assess the efficacy and safety of 3 doses of paliperidone palmitate in adults with acutely exacerbated schizophrenia. J Clin Psychopharmacol 2010; 30:235-244. [CrossRef]

20. Gaertner I, Altendorf K, Batra A, Gaertner HJ. Relevance of liver enzyme elevations with four different neuroleptics: a retrospective review of 7,263 treatment courses. J Clin Psychopharmacol 2001;21:215-22. [CrossRef]

21. Ouanes S, Damak R, Hajri M, Cherif W, Chennoufi L, Cheour M. Haloperidol-induced cytolytic hepatitis. Eur Psychiatry 2015;30 (Suppl 1):1597. [CrossRef]

22. Gabriel R, Wojtanowicz T, Farokhpay R, Bota R. Acute transaminitis after initial days of starting haloperidol. Ment Illn 2019;11:33-35. [CrossRef]

23. Saglam O, Bahsi R, Akkoca Y, Filik L. Risperidone-induced hepatotoxicity in a patient addicted to synthetic cannabinoid. Eur J Gastroenterol Hepatol 2016; 8:360-361. [CrossRef]

24. Yagcioglu EA, Gurel SC. Atypical antipsychotics: In Yuksel $\mathrm{N}$ (editor). Basic Psychopharmacology. Ankara: Psychiatric Association of Turkey Inc., 2010, 832-833. (Turkish)

25. Paulzen M, Orfanos S, Grunder G. Remission of drug-induced hepatitis after switching from risperidone to paliperidone. Am J Psychiatry 2010; 167:351-352. [CrossRef] 